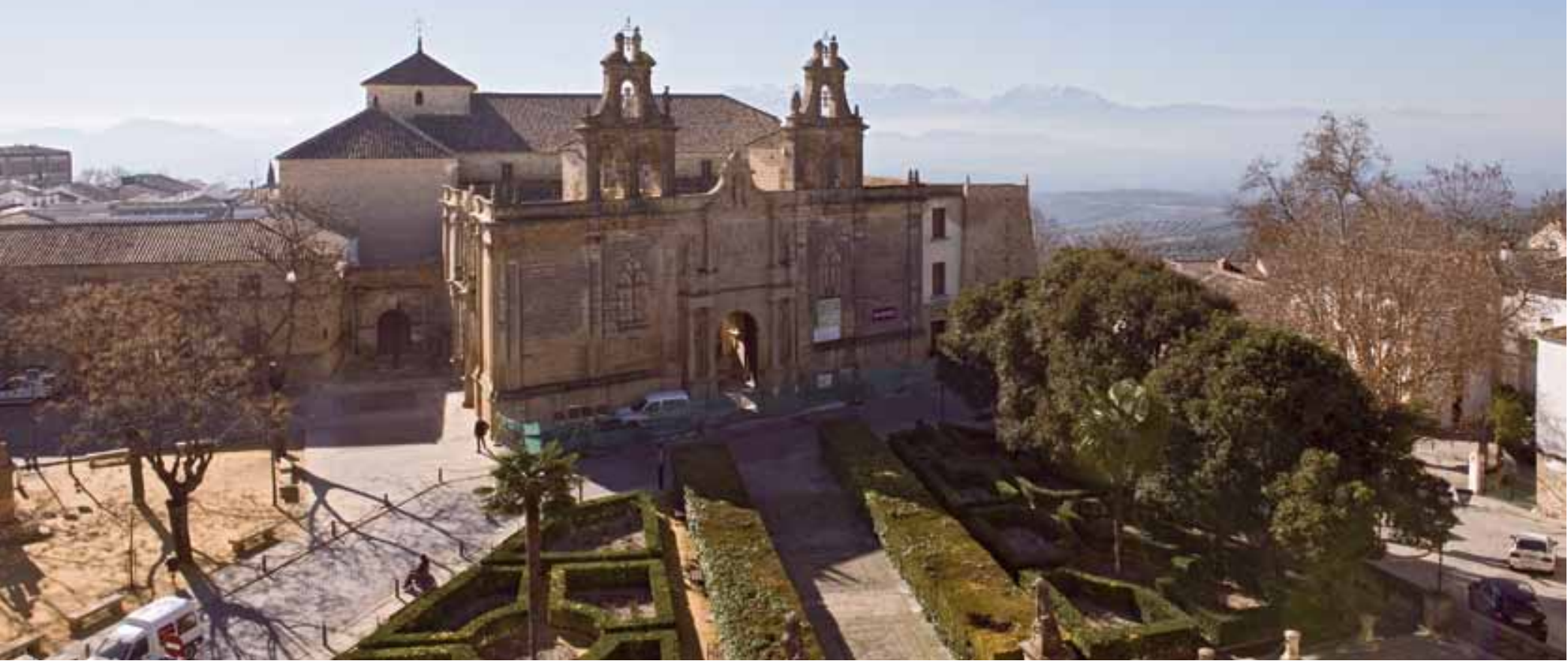

Plaza Vázquez Molina de Úbeda.

Fuente: Fondo Gráfico IAPH 


\section{Úbeda y Baeza Patrimonio Mundial}

\author{
Juan Manuel Becerra Garcia, jefe de \\ Servicio de Protección del Patrimonio \\ Histórico, Dirección General de Bienes \\ Culturales
}

El 3 de julio de 2003 el Comité Intergubernamental para la Protección del Patrimonio Mundial, Cultural y Natural, en su $27^{\circ}$ sesión ordinaria reunida en París, acuerda la inclusión de las ciudades de Úbeda y Baeza en la Lista Representativa del Patrimonio Mundial bajo la denominación de Conjuntos Monumentales Renacentistas de Úbeda y Baeza'. Para llegar hasta aquí fue necesaria la concurrencia de un importante equipo de especialistas cuyos trabajos pusieran de manifiesto los Valores Universales Excepcionales del sitio.

La Convención sobre la Protección del Patrimonio Mundial, Cultural y Natural de 1972 surge ante la necesidad de salvaguarda de los bienes culturales y naturales más representativos a escala mundial, y tiene su antecedente en los esfuerzos que se realizaron después de la Segunda Guerra Mundial para la conservación y rescate de monumentos de valor universal con el apoyo de la comunidad internacional, cuyo ejemplo más significativo lo tenemos en la campaña mundial que lanza la UNESCO para salvar los templos de Abu Simbel y Filae con motivo de la decisión del gobierno de Egipto de construir la presa de Asuán.

Conforme a las Directrices Prácticas ${ }^{2}$ para la aplicación de la Convención del Patrimonio Mundial, para que un sitio pueda ser incluido en la Lista Representativa del Patrimonio Mundial, debe poseer un Valor Universal Excepcional (VUE), es decir, tener una importancia cultural o natural extraordinaria que trascienda fronteras y un valor para las generaciones presentes y futuras de la humanidad.

"La excepcionalidad de las ciudades de Úbeda y Baeza estriba en que se desarrollan y estructuran a lo largo de la historia de forma dual. Una dualidad complementaria que las hace en muchos aspectos funcionar como una sola ciudad, con afinidades y rasgos propios y matices diferenciales que caracterizan su morfología y desarrollo histórico hasta el presente. Y todo ello, dentro de un ejemplar marco de convivencia y hermanamiento a lo largo del tiempo.

Separadas tan sólo por nueve kilómetros de distancia, con autonomía administrativa y funcional, alcanzaron durante el Re- nacimiento sus mejores y más bellas expresiones, fundiendo las concepciones humanistas con la base islámica en el urbanismo y la arquitectura y con el sustrato judio en la potenciación del humanismo a través de su Universidad como vehículo de expresión del conocimiento.

Dos ciudades cuya evolución histórica ha estado ligada a su condición de lugar de confluencias, posibilitando la generación de un espacio de libertades. Este diálogo entre corrientes y sustratos culturales ha generado aportaciones de amplia influencia -especialmente significativa en el arte de la cantería- no sólo en el ámbito territorial de la Península Ibérica, sino también en los nuevos espacios ultramarinos de la América española..."

Con estas líneas se inicia el documento de justificación de la inscripción de la candidatura que se incluye en el formulario que sirvió de soporte para la declaración como Patrimonio Mundial de las dos ciudades. En estas pocas palabras se condensan los principales argumentos de la propuesta.

\section{VALORES UNIVERSALES EXCEPCIONALES DE ÚBEDA Y BAEZA ${ }^{3}$}

Úbeda y Baeza mantienen una situación de paridad sin llegar a ensombrecerse la una a la otra hasta nuestros días. Es quizás esta dualidad $^{4}$ que se materializa en su emplazamiento físico, su patrimonio edificado, su morfología, paisaje y espacios urbanos, y su evolución paralela, uno de los aspectos más relevantes que caracterizan estas ciudades. Dualidad que se ha denominado complementaria, ya que Úbeda y Baeza hay que entenderlas como suma, como ciudades que responden a diferentes intereses no necesariamente antagónicos, resultado de un pulso de poderes: en Úbeda el poder civil, representado en la figura de Francisco de los Cobos, natural de Úbeda, poderoso y plenipotenciario secretario del Emperador Carlos V; y en Baeza, donde el poder eclesiástico se manifiesta en la existencia de sede episcopal, primera catedral de Andalucia, y una universidad con proyección cultural en todo el mundo hispano. 


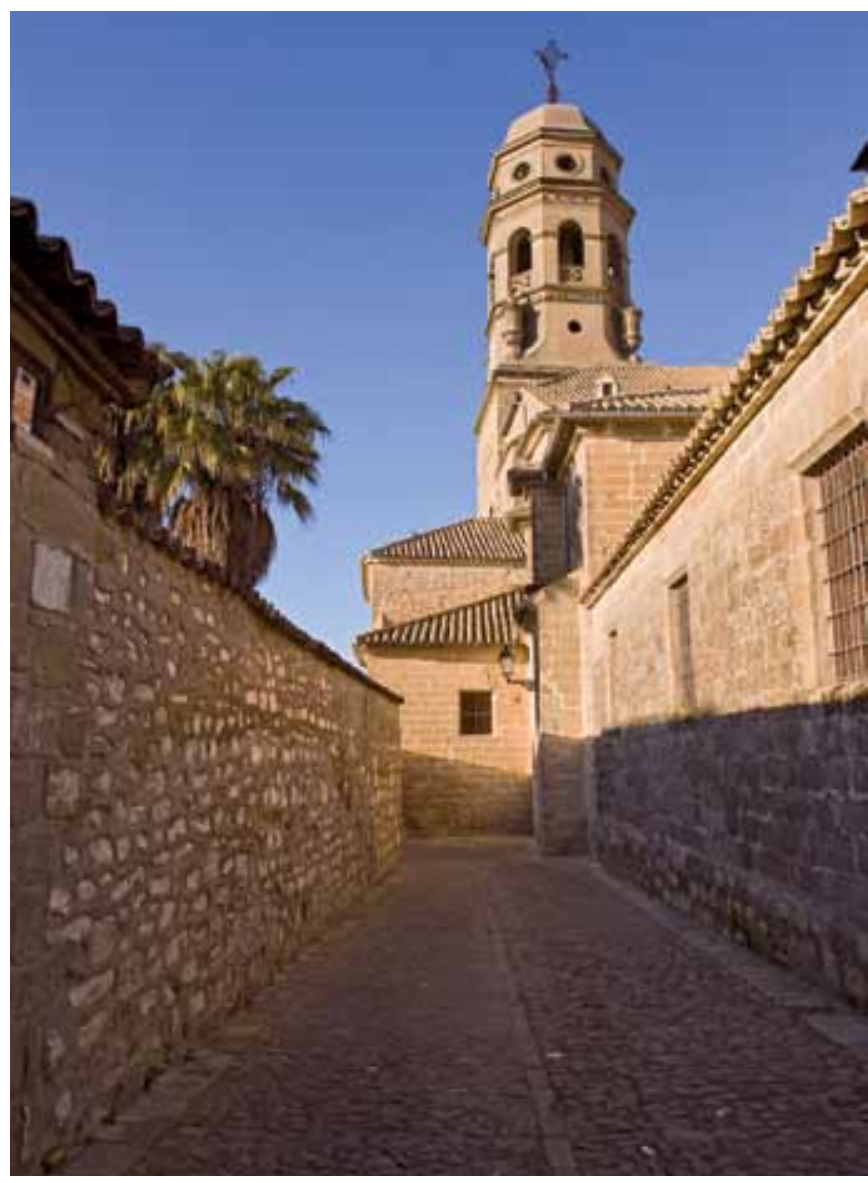

Catedral de Baeza

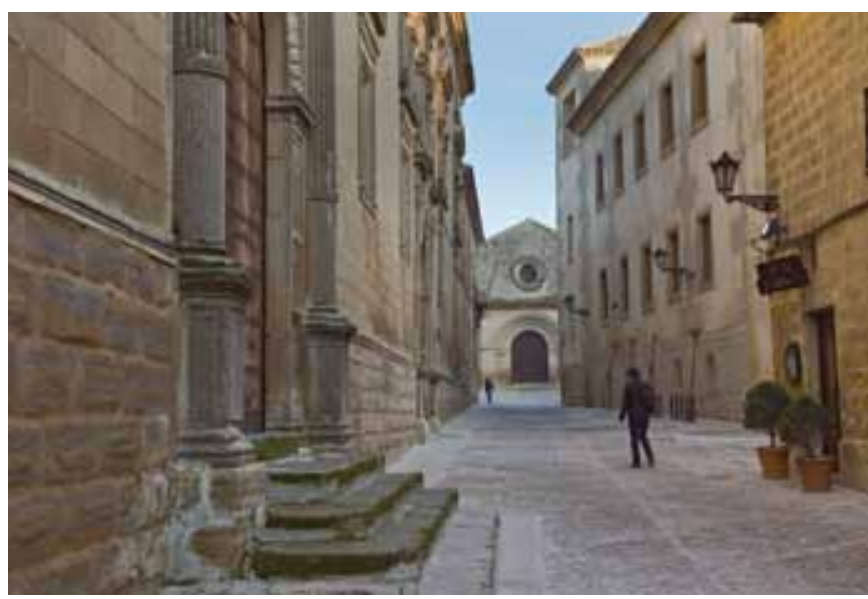

Calle Beato Ávila en Baeza

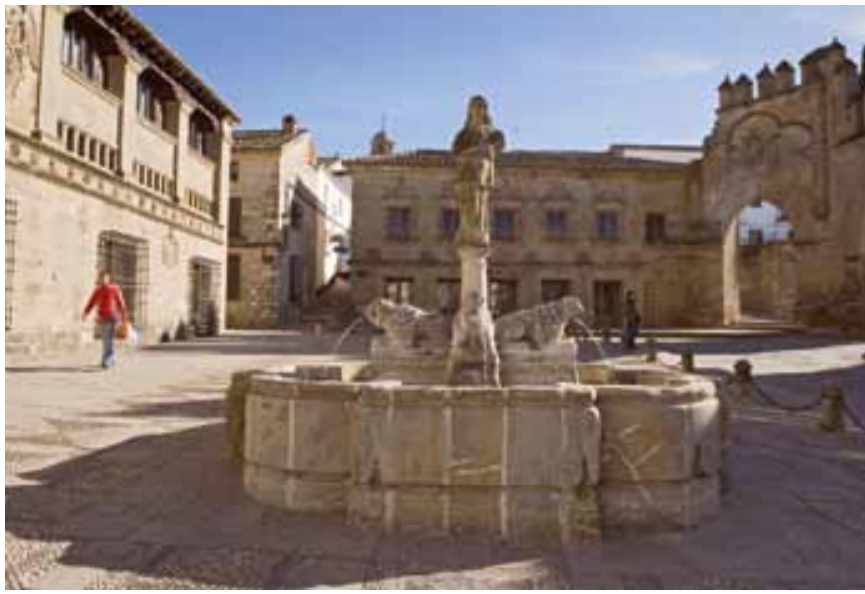

Plaza del Pópulo (Baeza)

Fuente: Fondo Gráfico IAPH
No obstante, es durante el Renacimiento cuando Úbeda y Baeza logran su mayor singularidad como ciudades. Así en Baeza se desarrolla una importante y numerosa arquitectura civil, mientras en Úbeda se aprecia un profundo desequilibrio entre la cantidad y calidad de la arquitectura señorial en forma de residencias y palacios y la parquedad de las construcciones públicas: ayuntamiento y pósito. Baeza convierte su ciudad intramuros en un gran centro eclesiástico y educativo con la catedral, la residencia del obispo, el seminario, el colegio de la Compañía de Jesús y la universidad a los que se une el palacio de Jabalquinto; mientras que Úbeda desarrolla sobresalientemente la arquitectura señorial en forma de residencias y palacios como los de Francisco de Cobos, Juan Vázquez de Molina, Deán Ortega o el del marqués de Mancera, 0 la sacra Capilla del Salvador.

Pero es quizás en la singularidad de su expresión artística, que une tradición e innovación en la figura de Andrés de Vandelvira, donde se expresa nuevamente la singularidad de estas ciudades. En el siglo XVI las dos ciudades alcanzan su mejor y mayor expresión a través de la arquitectura, perfilando un modelo urbanístico y arquitectónico singular, que asumiendo el sustrato medieval del que parten, se adentra en el lenguaje clásico propio del Renacimiento, reinterpretándolo e innovándolo. Se trata de la integración del lenguaje clásico con las técnicas tradicionales de la cantería local.

Andrés de Vandelvira es la figura que desarrollará el arte de la estereotomía en Úbeda y Baeza desde 1535. Su obra es el máximo exponente de las posibilidades que el dominio de la cantería tradicional, traducida con absoluta libertad a las formas clásicas, ofrecía a la "forma hispana de hacer arquitectura del Renacimiento". Asi el uso continuado por Vandelvira de la bóveda vaída, que tanto caracteriza al Clasicismo español y de la América española, se hace posible gracias a la renovación de la cantería. Este elemento fue utilizado en algunas de sus principales obras: catedral de Jaén, catedral de Baeza, iglesia del hospital de Santiago, y muy especialmente, en El Salvador de Úbeda.

Las aportaciones de Vandelvira en la estereotomía no sólo dejan reflejo en su obra material, sino que son recogidas en un tratado denominado Libro de Traças de cortes de piedra que redacta su hijo Alonso. No es un tratado en sentido estricto a la manera de los escritos teóricos italianos, sino un libro que parte de la experiencia práctica de la arquitectura por él construida, básicamente en Úbeda-Baeza. Este Libro, aunque no llegó a publicarse, está constatado que fue imitado y copiado gracias a versiones manuscritas durante todo el Antiguo Régimen. Visto desde hoy adquiere una importancia excepcional, ya que como dice Jean Marie Pérouse de Montclos, su riqueza es la mejor representación de la fecundidad de la arquitectura española del siglo XVI. Hasta bien entrado el siglo XVII no habrá nada en la teoría francesa que pueda igualársele. De hecho, frente a los 51 ejemplos que aporta Philibert De I'Orme en su tratado, Alonso de Vandelvira desarrolla 151 soluciones estereotómicas. 
Además, es reseñable el importante discurso iconológico desarroIlado en esta arquitectura, que adquiere una dimensión excepcional en el panorama español, al incorporar temáticas mitológicas (capilla de El Salvador, con testimonios iconográficos únicos en el arte español) o la inclusión de discursos judeoconversos (portada meridional del Salvador). En Úbeda y Baeza, dentro del discurso simbólico podemos encontrar desde la presencia erasmista hasta la perspectiva contrarreformista, en un reflejo de las tendencias que dominan el panorama nacional, e incluso europeo.

El ejemplo más completo de todo este rico y variado panorama y de la identidad arquitectónica de Úbeda y Baeza es la plaza Vázquez de Molina de Úbeda, espacio soporte de un grupo de construcciones civiles y religiosas, edificadas en un plazo de tiempo inferior a cincuenta años y que compone en términos de arquitectura el gran conjunto renacentista de España y uno de los más importantes del panorama europeo, impecable ejemplo de arquitectura renacentista, según Manfredo Tafuri.

Por último hay que resaltar la proyección en la América española de Úbeda y Baeza, que participan tanto en el aporte humano, como en la huella artística y cultural dejada. Varias de las obras americanas que forman hoy parte del patrimonio cultural mundial, como las catedrales de México, Puebla, Sucre y Lima, son tributarias de acciones cuyo origen se identifica con los procesos históricos-culturales sucedidos en las ciudades de Úbeda y Baeza.

El cantero baezano Ginés de Martínez de Aranda, autor de un tratado de corte de piedra y montea, a partir del manuscrito de Alonso de Vandelvira, asi como el ingeniero militar, también baezano, Cristóbal de Rojas con su primer tratado de fortificación en español, perfilan la línea argumental de lo que sería considerado "taller universal de canteria". El segundo tratado de Rojas Compendio y breve resolución de fortificación circuló profusamente en América como fuente de consulta, así como la utilización de las técnicas de casetonados y bóvedas vaídas difundidas en el siglo XVI y XVII desde los conocimientos desarrollados por Vandelvira, alcanzando una increible extensión en el continente operando en casos tan lejanos como las catedrales de México, Puebla, Mérida, Guadalajara, Oxaca, Lima y Cuzco, por citar sólo los ejemplos más destacados.

\section{Criterios de inscripción en la lista representativa}

Además del VUE, todo sitio candidato a patrimonio mundial debe al menos cumplir con uno de los diez criterios de inscripción, los seis primeros corresponden a los bienes culturales y los cuatro restantes a los bienes naturales. Los criterios de inscripción en el caso de Úbeda y Baeza fueron el (II) y (IV); es decir, atestiguar un intercambio de valores humanos considerable, durante un periodo concreto o en el área cultural del mundo determinada, en los ámbitos de la arquitectura o de la tecnología, las artes monumentales, la planificación urbana o la creación de paisajes (criterio II), y ser un ejemplo sobresaliente de un tipo de construcción, de conjunto arquitectónico o tecnológico, o de paisaje que ilustre

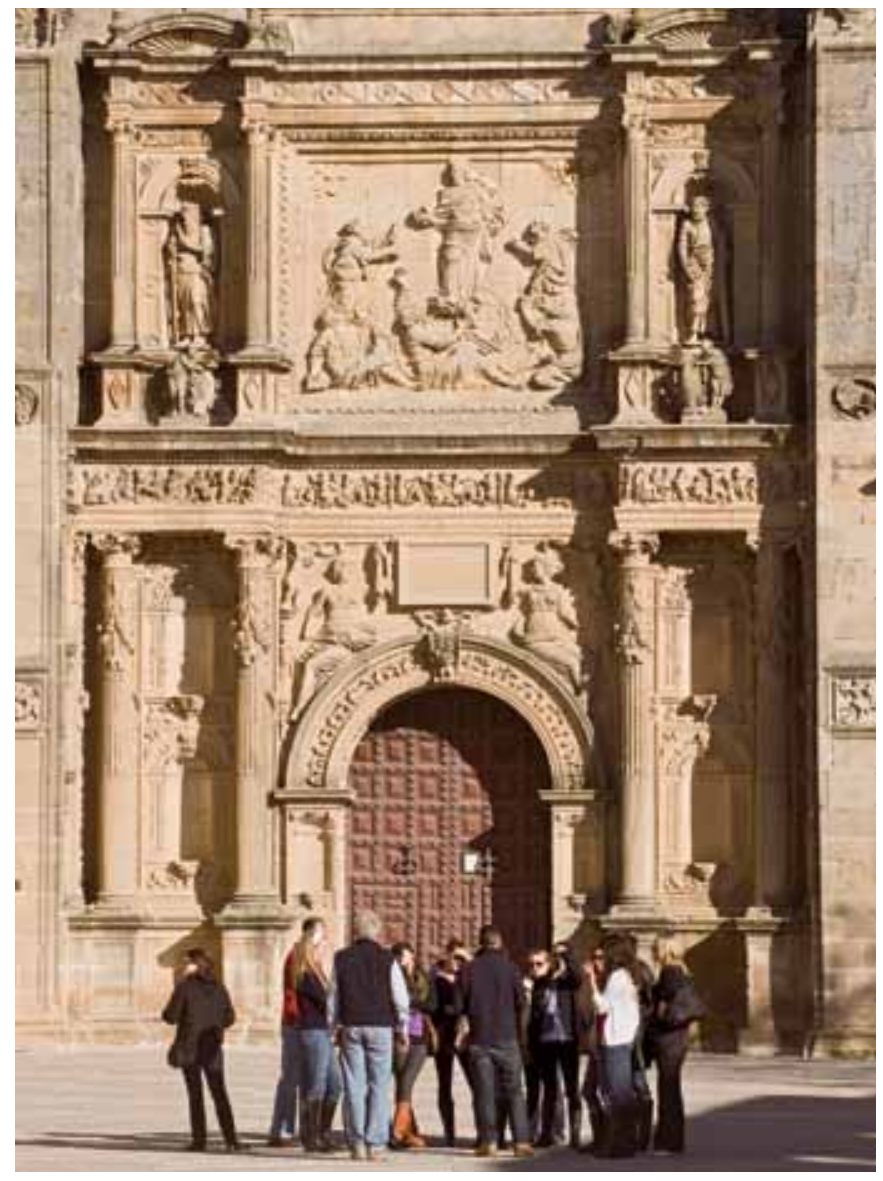

Iglesia del Salvador (Úbeda)

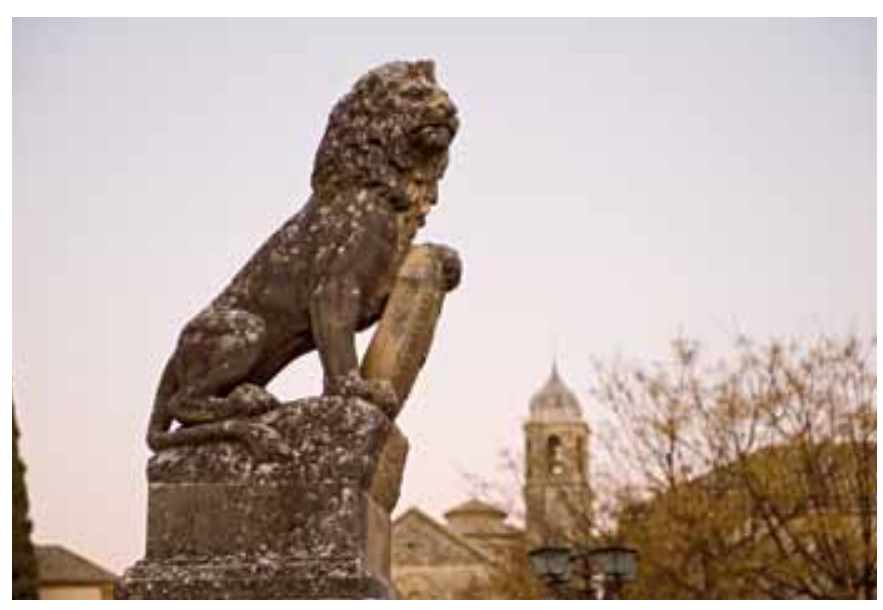

Úbeda

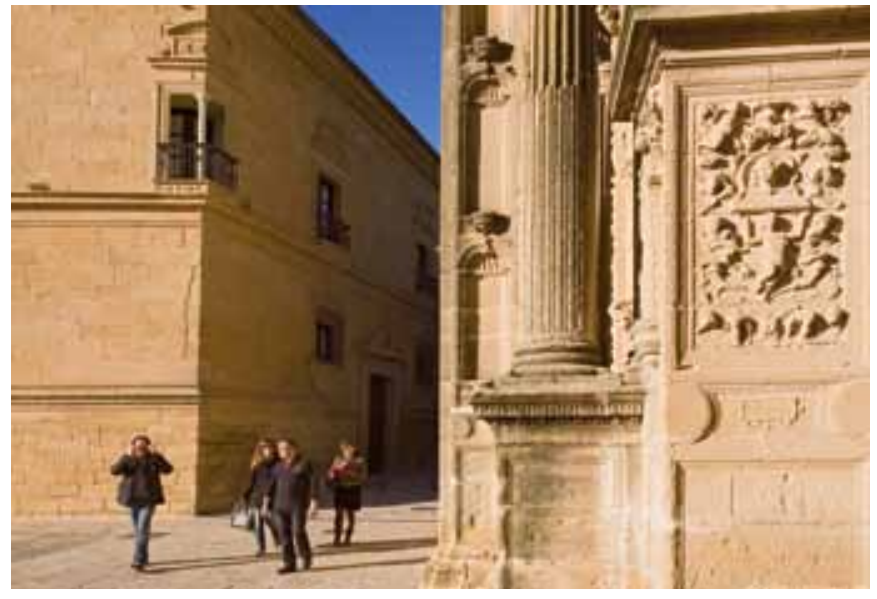

Úbeda.

Fuente: Fondo Gráfico IAPH 
BAEZA

Zona de Patrimonio de la Humanidad y zona de amortiguamiento

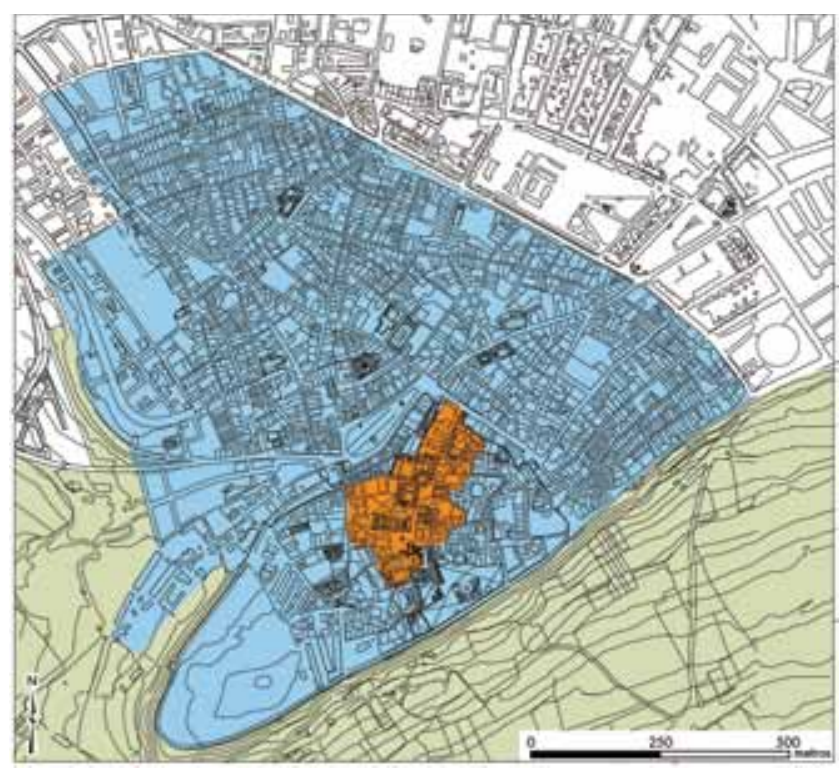

Zona Patrimonio de la Humanidad

Zona de amortiguamiento

"Casco extramuros"

"Entorno natural"

uno o varios periodos significativos de la historia humana (criterio IV). En concreto:

\section{Criterio (II).}

Los ejemplos de arquitectura y de diseño urbano del siglo XVI en Úbeda y Baeza fueron esenciales para la introducción de las ideas renacentistas en España y, a través de los tratados de estereotomía que recogen las innovaciones constructivas de Andrés de Vandelvira, el principal arquitecto de estos proyectos, estos ejemplos fueron también difundidos a América Latina, sirviendo de modelo de las principales catedrales e iglesias hispanoamericanas.

\section{Criterio (IV).}

Las áreas centrales de Úbeda y Baeza constituyen ejemplos tempranos y sobresalientes de la arquitectura civil y urbanismo renacentista de España en el siglo XVI. Conforman un completo esquema urbano renacentista de una gran calidad arquitectónica, que no se limita a una mera repetición de esquemas, sino que adquiere una identidad propia.

\section{¿Qué queda por hacer? Medidas de conservación del sitio}

Que un sitio se encuentre en la Lista del Patrimonio Mundial supone un reconocimiento mundial de sus valores culturales o natura-
ÚBEDA

Zona de Patrimonio de la Humanidad y zona de amortiguamiento

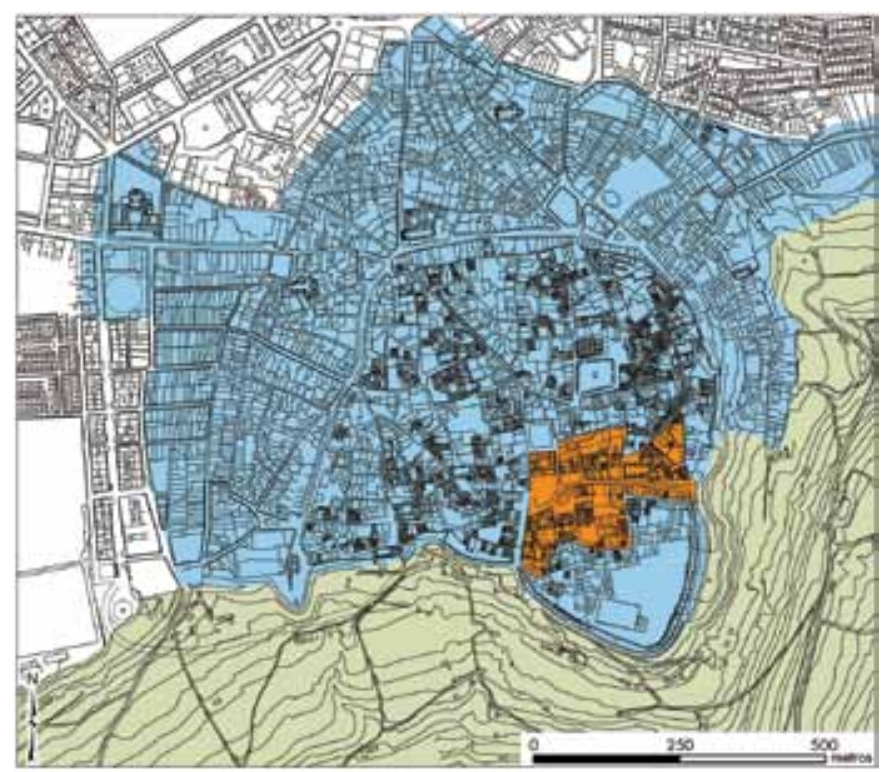

Zona Patrimonio de la Humanidad

Zona de amortiguamiento

"Casco extramuros"

"Entorno natural" les, y la entrada en un selecto club que también es muy exigente con sus miembros. Todo sitio Patrimonio Mundial debe ser un referente y un ejemplo de buen hacer en cuanto a la adopción de medidas de la conservación y mantenimiento de dicho sitio. Para ello, la UNESCO exige un compromiso efectivo tanto de las administraciones como de los individuos o entidades que participan del sitio, y propone la elaboración de planes de gestión que recojan las medidas e iniciativas necesarias para su correcta conservación, además de la creación de órganos mixtos de participación en la toma de decisiones y su seguimiento. En este sentido, los ayuntamientos de Úbeda y Baeza pueden considerarse ejemplares en cuanto a la iniciativa y ejecución de programas que han mejorado notablemente la conservación y percepción de los ámbitos declarados Patrimonio Mundial.

El mantenimiento del Valor Universal Excepcional queda garantizado al existir mecanismos de protección urbanística y patrimonial. Los ámbitos inscritos están incluidos en zonas declaradas conjunto histórico, y disponen de planes especiales de protección y catálogos urbanísticos. Además, los edificios singulares cuentan con el máximo nivel de protección existente en la legislación patrimonial, tanto regional como estatal, al estar declarados bienes de interés cultural en la categoria de monumentos. Los planes especiales y catálogos establecen las condiciones de protección 
a partir del criterio de mantenimiento de su estructura urbana y arquitectónica y de la imagen urbana tradicional. Tienen un contenido urbanístico amplio y no sólo protegen los valores mediante normativas especificas sino que proponen acciones de rehabilitación y recuperación urbana.

Los planes especiales han sido asumidos por los respectivos planes generales municipales: Úbeda (1997 y Revisión en avance 2009) y Baeza (1997 y Revisión próxima aprobación 2011), que promueven el valor de los conjuntos monumentales como centros funcionales y espacios simbólicos, además de proteger su entorno paisajístico. El planeamiento mantiene los usos actuales de los conjuntos monumentales y contempla actuaciones de mejora para los centros históricos: reactivación funcional y mejora de las condiciones de accesibilidad, movilidad peatonal y aparcamientos.

Mediante un acuerdo de colaboración de 1999, los ayuntamientos de Úbeda y Baeza han intentado desarrollar coordinadamente la gestión patrimonial en materias de conservación y rehabilitación, cultura y turismo, planteándose intervenciones sostenibles de recuperación de los respectivos centros históricos. Fruto de dicho acuerdo fueron la declaración de áreas de rehabilitación concertada de los respectivos centros históricos (Úbeda, 2005, y Baeza, 2006), que han supuesto numerosas actuaciones públicas en mejora de urbanización de espacios públicos, restauración de murallas y edificios singulares, rehabilitación de viviendas y dotación de equipamientos.

Desde marzo de 2009 esta coordinación se desarrolla mediante la Asociación para el desarrollo turístico de Úbeda y Baeza, que actualmente ejecuta el programa de turismo sostenible Úbeda y
Baeza, museo abierto del Renacimiento, según convenio suscrito con la Consejería de Turismo de la Junta de Andalucía. El programa prevé diversas actuaciones a desarrollar en cada ciudad, entre las que destacan el Plan integral de accesibilidad; la creación de aparcamientos disuasorios, restricciones del tráfico rodado; urbanización de espacios públicos, señalización patrimonial; etc. Con esta línea de actuación, se ha pretendido hacer de Úbeda-Baeza un modelo de gestión patrimonial de ciudades medias andaluzas.

Por último, no existen expectativas que supongan una amenaza de los valores patrimoniales.

\section{Notas}

1 La resolución por la que declaran Patrimonio Mundial las ciudades de Úbeda y Baeza se encuentra recogida en la Decisión -27COM 8C.42- Renaissance Monumental Ensembles of Úbeda and Baeza, pudiéndose consultar en la dirección http://whc.unesco.org/en/decisions/737

${ }^{2}$ Las directrices prácticas operativas vienen a ser como el reglamento que pormenoriza y desarrolla la Convención. Las directrices que actualmente se encuentran en vigor fueron aprobadas en 2008 y pueden ser consultadas en la dirección http:// whc.unesco.org/archive/opguide08-en.pdf, en la versión inglesa, y en la dirección http://whc.unesco.org/archive/opguide08-fr.pdf en la versión francesa.

${ }^{3}$ Sin pretender ser exhaustivo, en este apartado se hace un breve resumen de los principales argumentos con los que el formulario de la declaración pretende justificar los valores excepcionales universales de Úbeda y Baeza. Para un mayor conocimiento se recomienda la lectura de la documentación del expediente que fue publicado por la Dirección General de Bienes Culturales de la Consejería de Cultura. Conjuntos Monumentales de Úbeda-Baeza, Patrimonio Mundial. Enclave dual del Renacimiento Español. ISBN 84-8266-411-5, Sevilla 2003.

${ }^{4}$ El hecho de la dualidad es uno de los rasgos más distintivos de la candidatura, llegando a recogerse incluso en el título con la que la misma se presenta ÚbedaBaeza: dualidad urbana, unidad cultural.

\section{En la web}

\section{ÚBEDA. CIUDAD DEL RENACIMIENTO www.ubedaturismoypatrimonio.es/ UbedaCiudadDigital}

Recreación virtual de Úbeda como ciudad del Renacimiento y cruce de culturas. A través de este sitio web podrá navegar por los monumentos más representativos de la Úbeda del Renacimiento. El sitio web ofrece dos itinerarios: Ciudad del Renacimiento y Cruce de Culturas. En cada uno de ellos podrá acceder a cada una de las entidades patrimoniales con fichas informativas que incluyen imágenes y reconstrucciones. Del igual modo el sitio ofrece dos visitas virtuales a la plaza Primero de Mayo y plaza Vázquez de Molina.

\section{PATRIMONIO MUNDIAL EN ESPAÑA}

www.patrimonio-mundial.com

Noticias, documentación, normativa todo lo relacionado con las inscripciones de patrimonio mundial por la UNESCO en España se puede encontrar en este sitio web. Bienes españoles inscritos en la Lista de Patrimonio Mundial en la que se incluye "Dualidad urbana y unidad cultural de Úbeda y Baeza".

\section{INSTITUTO DE ESTUDIOS} GIENNENSES

www.dipujaen.es/conoce-diputacion/ areas-organismos-empresas/ieg

Sección del sitio web de la Diputación Provincial de Jaén dedicada al Instituto de Estudios Gienneses. Podrá acceder a los fondos bibliográficos de este organismo a través de su catálogo online así como consultar los números de su boletín a través de un buscador.

\section{CENTRO ANDALUZ DE} AROUEOLOGÍA IBÉRICA www.ujaen.es/centros/caa

Organismo dedicado a la investigación, conservación, gestión y difusión de la arqueología ibérica de Andalu- cía. Proyectos de investigación propios y de otras instituciones del ámbito temático, rutas, noticias, enlaces, formación forma parte de los recursos de este sitio web.

\section{PATRIMONIO OLEÍCOLA}

www.patrimonioleicola.com

Proyecto desarrollado por los diversos agentes vinculados al desarrollo local de la provincia de Jaén, con el fin de poner en valor los elementos materiales e inmateriales que componen el patrimonio natural y cultural oleícola. El sitio web ofrece información sobre las comarcas y un visor cartográfico con los elementos más representativos del patrimonio oleícola (almazaras en uso, cortijos y molinos, etc.). Entre sus recursos de información se encuentran publicaciones, imágenes, videos y audios.

\section{PORTAL DE LA COMARCA DE SIERRA MÁGINA \\ www.magina.org}

Completo portal web que permite conocer a fondo la comarca de sierra Mágina; población y sociedad, actividades económicas, historia y arquitectura, cultura y tradiciones. Podrá acceder a información sobre sus municipios; extensión, población, historia, arte, gastronomía, fiestas, etc. 